\title{
CBX3/HP1 $\gamma$ is upregulated in tongue squamous cell carcinoma and is associated with an unfavorable prognosis
}

\author{
HUAYONG ZHANG ${ }^{1,2^{*}}$, XIAOYAN FU $^{1 *}, \mathrm{XUAN} \mathrm{SU}^{1}$ and ANKUI YANG ${ }^{1}$ \\ ${ }^{1}$ Department of Head and Neck Surgery, Sun Yan-sen University Cancer Centre, Guangzhou, Guangdong 510000; \\ ${ }^{2}$ Department of Cardiothoracic Surgery, The Fifth Affiliated Hospital of Sun Yan-sen University, \\ Zhuhai, Guangdong 519000, P.R. China
}

Received November 1, 2017; Accepted March 13, 2018

DOI: $10.3892 /$ etm.2018.5969

\begin{abstract}
Increased expression of $\mathrm{CBX} 3 / \mathrm{HP} 1 \gamma$, a core component of heterochromatin protein 1 , has recently proved to be involved in human tumorigenesis and patient prognosis. The present study aimed to investigate the expression of $\mathrm{CBX} 3 / \mathrm{HP} 1 \gamma$ and its clinicopathological significance in primary tongue squamous cell carcinoma (TSCC). Gene expression profiles of CBX3/HP1 $\gamma$ in TSCC from Oncomine database were analyzed. The expression of $\mathrm{CBX} 3 / \mathrm{HP} 1 \gamma$ at protein level was measured using immunohistochemistry (IHC). The potential associations between CBX3/HP $1 \gamma$ expression and multiple clinicopathological parameters were estimated using the Chi square test. In addition, the effect of CBX3/HP1 $\gamma$ expression on patients' survival was further assessed by Kaplan-Meier and Cox regression analyses. The agreement of elevated CBX3/HP1 $\gamma$ expression was indicated in four datasets on the Oncomine database. Aberrant overexpression of CBX3/HP1 $\gamma$ was identified in TSCC tissues compared with cancer-adjacent normal tissue, which was significantly associated with cervical nodes metastasis $(\mathrm{P}=0.010)$ and clinical stage $(\mathrm{P}=0.025)$. Furthermore, patients with high $\mathrm{CBX} 3 / \mathrm{HP} 1 \gamma$ expression exhibited a reduced survival compared with those with low expression (Log-rank test, $\mathrm{P}=0.004$ ). Univariate and multivariate Cox regression analysis suggested that the expression status of $\mathrm{CBX} 3 / \mathrm{HP} 1 \gamma$ could be regarded as an independent prognostic factor for TSCC patients $(\mathrm{HR}=2.461$; 95\% CI=1.128-5.370; $\mathrm{P}=0.024)$. The present study indicated that aberrant overexpression of $\mathrm{Cbx} 3 / \mathrm{HP} 1 \gamma$ was associated with cervical nodes metastasis and unfavorable survival in TSCC. These findings suggest that $\mathrm{CBX} 3 / \mathrm{HP} 1 \gamma$ may serve
\end{abstract}

Correspondence to: Professor Ankui Yang, Department of Head and Neck Surgery, Sun Yan-sen University Cancer Centre, 651 Dongfeng East Road, Guangzhou, Guangdong 510000, P.R. China

E-mail: ankuiyang@foxmail.com

*Contributed equally

Key words: tongue neoplasms, prognosis, $\mathrm{Cbx} 3 / \mathrm{HP} 1 \gamma$ an important role in tongue tumorigenesis and may be a valuable candidate diagnostic and prognostic marker for TSCC patients.

\section{Introduction}

Tongue squamous cell carcinoma (TSCC) is the most common malignancy in the oral cavity, accounting for about one-third of all oral cancers (1). The morbidity and typical mortality rates of TSCC has been increasing rapidly during the past five years $(2,3)$. Being an aggressive subtype of oral cancer, TSCC is characterized by high frequency of local invasion and occult lymph node metastasis. Consequently, the long-term survival rate continue to be low, with the overall five-year survival rate at the level of less than $50 \%$ (4). Therefore, identification of novel biomarkers and therapeutic targets against TSCC is necessary and urgent to illustrate the clinical behavior of TSCC and to personalize therapy.

The heterochromatin proteins 1 (HP1) family, known as chromatin binding proteins, directly bind to the promoter region of the methylated $\mathrm{H} 3 \mathrm{~K} 9$ (the methyl groups of histone $\mathrm{H} 3$ at lysine 9) to participate in the heterochromatin silence of gene expression (5). Recent studies indicated that H3K9 methylation may play key roles in tongue cancer tumorigenesis (6). HP1 $\gamma$, encoded by the CBX3, is a paralog of HP1. By binding methylated $\mathrm{H} 3 \mathrm{~K} 9, \mathrm{CBX} 3 / \mathrm{HP} 1 \gamma$ can recruit lots of cofactors which perform various biological functions including RNA alternative splicing, DNA damage response, transcription elongation, cell growth and differentiation (7). Moreover, $\mathrm{CBX} 3 / \mathrm{HP} 1 \gamma$ is also located in euchromatin areas, which suggest that it may be also associated wih transcriptional activation (8). Previous studies proved that CBX3/HP1 $\gamma$ was abnormally expressed in multiple cancers such as prostate, colon and lung cancer (9-11), and was always an unfavorable prognostic factor. Thus, it seems that $\mathrm{CBX} 3 / \mathrm{HP} 1 \gamma$ plays a potential role as a novel cancer biomarker and a putative oncogene. However, the expression level of $\mathrm{CBX} 3 / \mathrm{HP} 1 \gamma$ in TSCC and its clinical pathologic parameters remains unclear.

Herein, we sought to investigate the expression of CBX3/HP1 $\gamma$ in primary human TSCC specimens and identify potential relationship between its expression and clinicopathological features as well as patients' survival. 


\section{Materials and methods}

Oncomine database analysis. To obtain the outline of the $\mathrm{CBX} 3 / \mathrm{HP} 1 \gamma$ expression pattern, we explored the CBX3 mRNA levels of human TSCC in Oncomine database (http://www.oncomine.org), which is publicly available.

Patients and specimen collection. A cohort of 126 patients with primary TSCC treated in Sun Yat-sen University Cancer Center between January 2009 and December 2010 were enrolled retrospectively. The enrollment criteria included: i) primary TSCC without any chemotherapy or radiotherapy before surgery; ii) patients underwent radical tumor resection and neck dissection and iii) complete information available about clinical, pathological and follow-up data. The formalin-fixed paraffin-embedded samples were collected from the archives of the hospital, with adjacent non-tumor tissues from the same patients as a control group. Cancer stage was defined according to the TNM staging based on American Joint Committee on Cancer (AJCC), 7th edition (12). In order to verify the diagnosis, histological grade and stage, all samples were reviewed by a pathologist. This study was under the approval of the Clinical Research Ethics Committee of Sun Yat-sen University Cancer Center. Informed consent was obtained from all patients.

Immunohistochemistry (IHC). IHC studies were performed on formalin-fixed, paraffin-embedded specimens following routine procedure. In brief, $3 \mu \mathrm{m}$-thick tissue sections were deparaffnized in xylene and hydrated in graded alcohol ranging from 100,95 , and 80 to $70 \%$. Endogenous peroxidase activity was blocked with $3 \%$ hydrogen peroxide for $10 \mathrm{~min}$, and then washed with phosphate-buffered saline (PBS, pH 7.3). Antigen retrival was completed by boiling in citric acid buffer $(10 \mathrm{mM}$, $\mathrm{pH}$ 6.0) for $15 \mathrm{~min}$. In order to block nonspecific binding, slides were incubated with $10 \%$ normal goat serum for $15 \mathrm{~min}$ at room temperature. These sections were in further incubation of a rabbit anti-CBX3 antibody (diluted 1:400 in PBS; Wuhan Sanying Biotechnology, Wuhan, China) overnight at $4^{\circ} \mathrm{C}$, following with incubation of secondary anti-rabbit antibody at a concentration of $1: 100$ at $37^{\circ} \mathrm{C}$ for $30 \mathrm{~min}$. Subsequently, the sections were washed with PBS, colorized by diaminobenzidine (DAB) solution and counterstained with haematoxylin. PBS was used to replace the primary antibody as a negative control, whereas known IHC-positive CBX3/HP1 $\gamma$ staining slides of colon cancer were used as positive control.

The immunoreactivity was scored independently by two pathologists insensible of relevant clinicopathological data according to the stained intensity of cancer cells and positively-stained proportion. The estimated fraction of positive-stained tumor cells was defined as the proportion score $(0$, none; $1,10 \% ; 2,11-50 \% ; 3,51-80 \% ; 4,>80 \%)$, whereas the estimated staining intensity was demonstrated as the intensity score ( 0 , no staining; 1 , weak; 2 , moderate; 3 , strong) with the aggregate score ranging from 0 to 12 , as described elsewhere (13). Overexpression of $\mathrm{CBX} 3 / \mathrm{HP} 1 \gamma$ was defined as an aggregate score of $>4$. Therefore, the immunoreactivity of each slide was categorized into three subgroups based on the final score: negative (0); low expression (1-4); high expression (6-12).
Statistical analyses. Comparisons of raw IHC outcomes between groups were performed using the Wilcoxon signed-rank test. The Chi-square test was used to evaluate the associations between clinicpathological parameters of patients and $\mathrm{CBX} 3 / \mathrm{HP} 1 \gamma$ expression. The overall survival was analyzed using Kaplan-Meier method and compared with Log-rank test. Univariate and multivariate Cox regression models were used to estimate individual clinical and pathological variables with patients' overall survival. P-values $<0.05$ (two-sided) were considered to indicate a statistically significant difference. All statistical analyses were performed using Graphpad Prism 5 (GraphPad Software, Inc., La Jolla, CA, USA) or SPSS v24.0 (IBM Corp., Armonk, NY, USA).

\section{Results}

mRNA expressing pattern of CBX3 on oncomine database. We explored the mRNA expression of CBX3 in 4 datasets on Oncomine Database (Fig. 1). CBX3 mRNA was found significantly elevated in human TSCC tissues compared with normal tissues in datasets from Oncomine Database [Talbot et al (14), Estilo et al (15), Kuriakose et al (16) and Ye et al (17)]. We noticed that the number of cases examined in each group was quite different. For example, in Kuriakose's group, there are only 3 cancer cases against 22 normal controls. However, the data from study came to a consistent result that CBX3 mRNA significantly elevated in human TSCC tissues.

Overexpression of CBX3/HPI $\gamma$ at protein level in TSCC tissues. The CBX3/HP1 $\gamma$ protein expression of all TSCC tissues and adjacent non-tumor tissues were evaluated by IHC. The representative immunohistochemical staining of $\mathrm{CBX} 3 / \mathrm{HP} 1 \gamma$ in TSCC and adjacent tongue mucosa was shown in Fig. 2A. High CBX3/HP1 $\gamma$ expression was mainly located in the nucleus areas rather than the cytoplasm in cancer cells, whereas weak or negative staining was observed in normal tongue epithelial cells. According to our IHC scoring regime, $\mathrm{CBX} 3 / \mathrm{HP} 1 \gamma$ protein abundance in these primary TSCC and adjacent tissues was categorized, respectively. These data showed that $\mathrm{CBX} 3 / \mathrm{HP} 1 \gamma$ was significantly overexpressed in TSCC than in the adjacent tissues ( $\mathrm{P}<0.001$; Fig. 2B).

Association between CBX3/HPI $\gamma$ expression and clinicopathological characteristics. The association between $\mathrm{CBX} 3 / \mathrm{HP} 1 \gamma$ expression and clinical pathological characteristics (age, gender, smoking, pathological grade, T stage, TNM stage, cervical node status) were summarized in Table I. Briefly, 82 male and 44 female patients were enrolled with mean age 54.1 years (25-83 years). The follow-up period ranged from 6.5 to 97.8 months with average 67.6 months. The results showed that cervical node metastasis $(\mathrm{P}=0.010)$, clinical stage $(\mathrm{P}=0.025)$ were related to high $\mathrm{CBX} 3 / \mathrm{HP} 1 \gamma$ expression (Table I). There were no significant correlations between CBX3/HP1 $\gamma$ expression with patients' age, gender, smoking state, tumor size and pathological grade (Chi square test).

Association between CBX3/HPI $\gamma$ expression and overall survival of TSCC patients. The correlation between CBX3/HP1 $\gamma$ expression and patients' survival was analyzed 
A

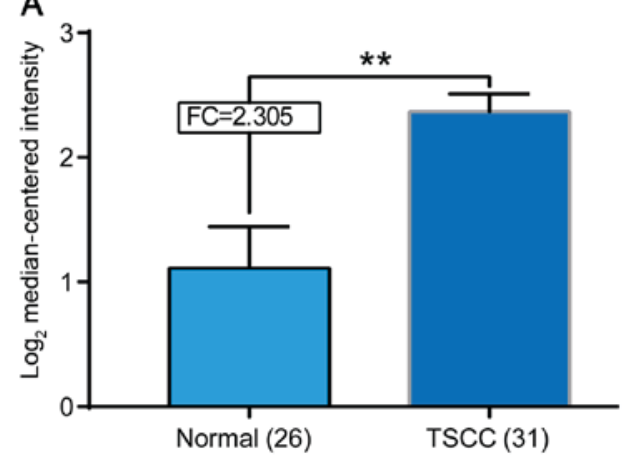

C

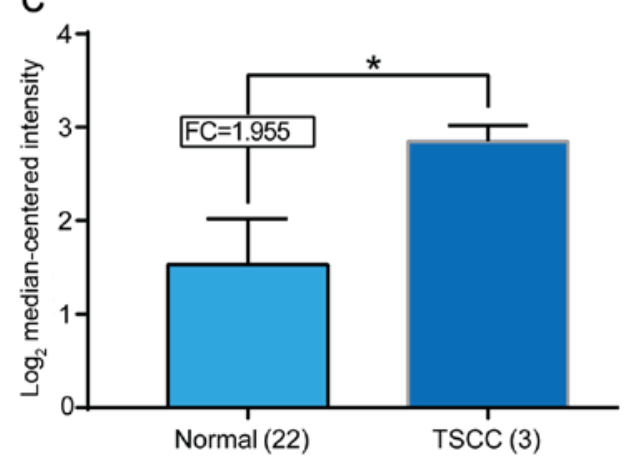

B

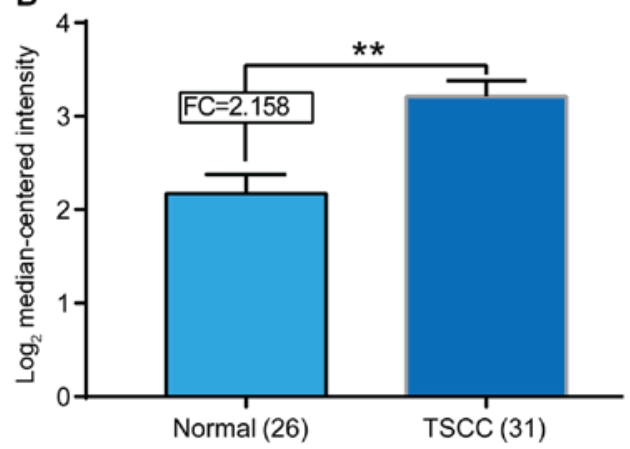

D

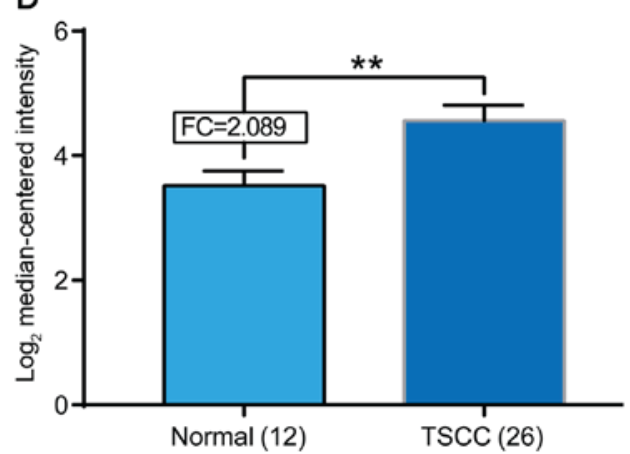

Figure 1. Search for Cbx3 mRNA expression of TSCC in Oncomine database. The mRNA levels of Cbx3 of TSCC were elevated in different datasets. The different datasets from the researchers (A) Talbot et al (14), (B) Estilo et al (15), (C) Kuriakose et al (16) and (D) Ye et al (17), who provide the data in Oncomine were indicated. The expression level of CBX3 mRNA was indicated in the form of $\log 2$ median-centered intensity. ${ }^{*} \mathrm{P}<0.05,{ }^{* *} \mathrm{P}<0.01$. FC, fold change.
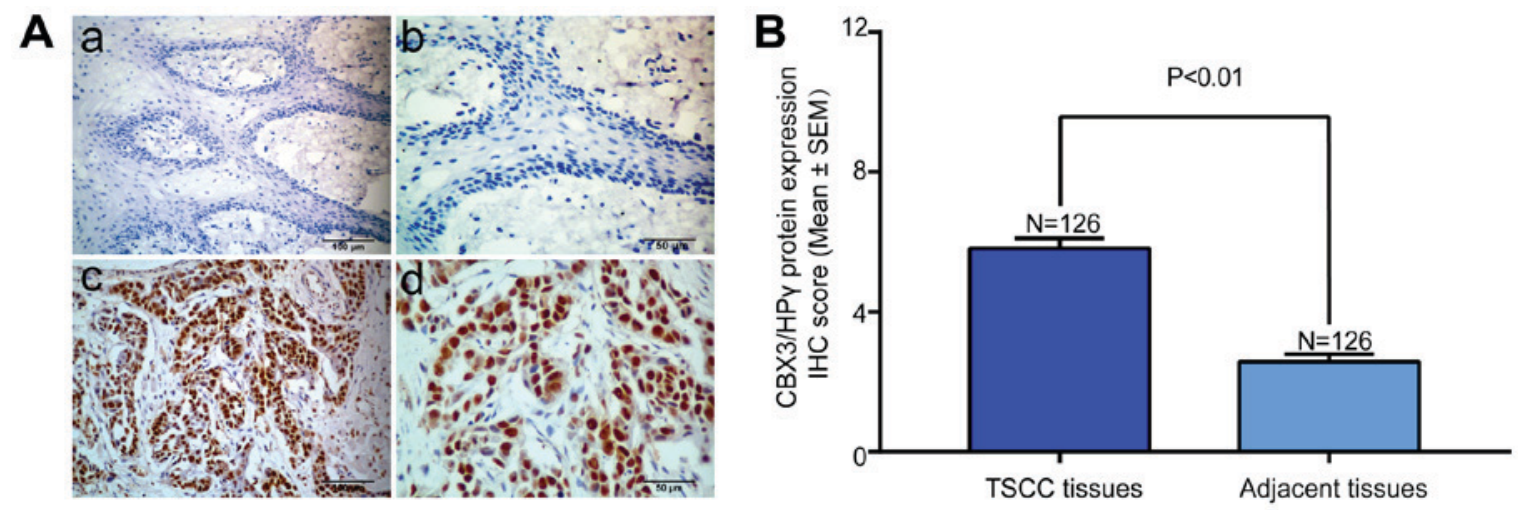

Figure 2. Immunohistochemical staining of CBX3/HP1 $\gamma$ protein in TSCC tissues and cancer-adjacent normal tissue. (Aa) Representative weak staining of CBX3/HP1 $\gamma$ (low expression) in cancer-adjacent normal tissue (magnification, x200). Nuclei were counterstained with hematoxylin. (Ab) Magnified image from a (magnification, $\mathrm{x} 400$ ). (Ac) Representative strong staining of CBX3/HP1 $\gamma$ (high expression) in primary TSCC sample (magnification, x200). (Ad) Magnified image from c (magnification, x400). CBX3/HP1 $\gamma$ expression was identified primarily in nuclei of cancer cells. (B) Statistical analysis of CBX3/HP1 $\gamma$ IHC scores in TSCC tissues and cancer-adjacent normal tissue. Data was presented as the mean with SEM.

to uncover the potential prognostic value of $\mathrm{CBX} 3 / \mathrm{HP} 1 \gamma$ expression. Up to the last follow-up, 85 of $126(67.5 \%)$ patients were alive, $41(32.5 \%)$ patients died of cancer recurrence or metastases. The Kaplan-Meier survival analyses showed that high CBX3/HP1 $\gamma$ expression indicated unfavorable outcomes. As shown in Fig. 3, patients with low CBX3/HP1 $\gamma$ expression had significantly better overall survival than those with high expression (Log-rank test, $\mathrm{P}=0.004)$.

We conducted the univariate and multivariate survival analyses to further evaluate the clinical significance of CBX3/HP $1 \gamma$ expression as a prognostic predictor for TSCC patients. The univariate survival analysis revealed that CBX3/HP1 $\gamma$ expression status, cervical node metastasis and clinical stage were significantly associated with overall survival, while other clinicopathological parameters had not reached the statistical significance. Furthermore, multivariate survival analysis was also performed to exclude the confounding factors. Both the $\mathrm{CBX} 3 / \mathrm{HP} 1 \gamma$ expression status $(\mathrm{HR}=2.461 ; 95 \%$ CI 1.128-5.370; $\mathrm{P}=0.024)$ and clinical stage ( $\mathrm{HR}=3.663 ; 95 \% \mathrm{CI} 1.322-10.146 ; \mathrm{P}=0.013$ ) were identified as an independent prognostic factor for the overall survival of patients with TSCC in this Cox regression model (Table II). 
Table I. Associations between CBX3/HP1 $\gamma$ expression and multiple clinicopathological parameters in primary TSCC.

\begin{tabular}{|c|c|c|c|c|}
\hline \multirow[b]{2}{*}{ Variables } & \multirow[b]{2}{*}{ Cases } & \multicolumn{2}{|c|}{$\mathrm{CBX} 3 / \mathrm{HP} 1 \gamma$ expression } & \multirow[b]{2}{*}{$\chi^{2} \mathrm{P}$-value } \\
\hline & & Low $^{\mathrm{a}}$ & High & \\
\hline Age & & & & 0.182 \\
\hline$<60$ & 81 & 28 & 53 & \\
\hline$\geq 60$ & 45 & 21 & 24 & \\
\hline Gender & & & & 0.273 \\
\hline Male & 80 & 34 & 46 & \\
\hline Female & 46 & 15 & 31 & \\
\hline Smoking & & & & 0.745 \\
\hline Yes & 64 & 24 & 40 & \\
\hline No & 62 & 25 & 37 & \\
\hline Tumor size & & & & 0.843 \\
\hline $\mathrm{T} 1-2$ & 107 & 42 & 65 & \\
\hline $\mathrm{T} 3-4$ & 19 & 7 & 12 & \\
\hline Pathological grade & & & & 0.824 \\
\hline $\mathrm{G} 1$ & 99 & 38 & 61 & \\
\hline $\mathrm{G} 2-3$ & 27 & 11 & 16 & \\
\hline Cervical node metastasis & & & & 0.010 \\
\hline $\mathrm{N}-$ & 89 & 41 & 48 & \\
\hline $\mathrm{N}+$ & 37 & 8 & 29 & \\
\hline Clinical stage & & & & 0.025 \\
\hline I-II & 80 & 37 & 43 & \\
\hline III-IV & 46 & 12 & 34 & \\
\hline
\end{tabular}

${ }^{a}$ Both of patients with low and negative $\mathrm{CBX} 3 / \mathrm{HP} 1 \gamma$ staining are stratified into low category for simplicity. TSCC, tongue squamous cell carcinoma.

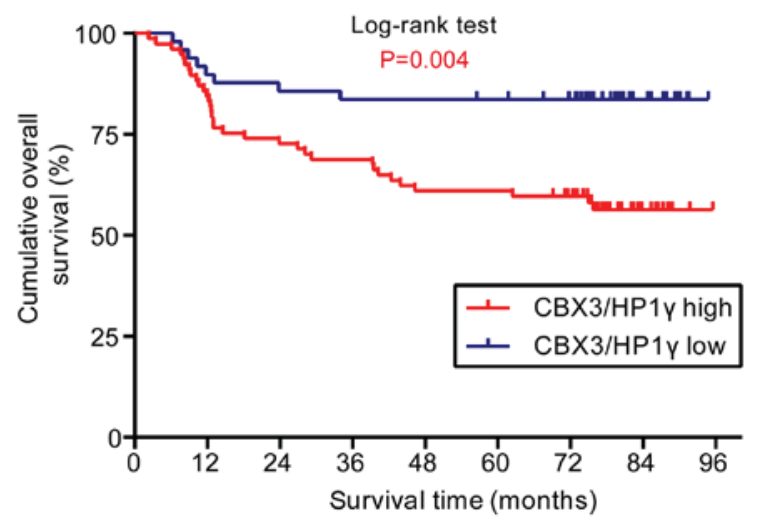

Figure 3. Overexpression of $\mathrm{CBX} 3 / \mathrm{HP} 1 \gamma$ protein was associated with poor overall survival in patients with TSCC. Kaplan-Meier curves for overall survival rate in 126 patients with TSCC according to the expression status of $\mathrm{CBX} 3 / \mathrm{HP} 1 \gamma$. The staining score (6) served as a cut-off to divide patients into high and low expression. Blue line: Patients with low CBX3/HP1 $\gamma$ expression, red line: Patients with high $\mathrm{CBX} 3 / \mathrm{HP} 1 \gamma$ expression. High $\mathrm{CBX} 3 / \mathrm{HP} 1 \gamma$ protein expression was associated with significantly reduced overall survival $(\mathrm{P}=0.004$, Log-rank test).

\section{Discussion}

Being a key hallmark of human cancer, aberrant epigenetic alternations including histone modification are significantly involved in multiple stages of oncogenesis (18). HP1, a well-known marker of histone modification for transcriptionally silenced heterochromatin (19), is reported to have various cellular functions including heterochromatin formation, chromatin remodeling, transcription regulation, DNA damage repairing and cancer progression (20-22). Previous studies have suggested that the CBX3/HP1 $\gamma$, one paralog of HP1, might be an oncogene driving tumorigenesis and a novel diagnostic and prognostic biomarker in multiple cancers $(11,23-25)$. Herein we investigated the expression pattern of $\mathrm{CBX} 3 / \mathrm{HP} 1 \gamma$ in primary TSCC and its clinical pathological relevance and prognostic significance. We found that $\mathrm{CBX} 3 / \mathrm{HP} 1 \gamma$ was aberrantly overexpressed in TSCC tissues than in normal tissues and its overexpression was significantly related to aggressive clinical pathological parameters and an unfavorable prognosis. This result was consistent with the trend in other cancers $(11,25)$.

Tumorigenesis of TSCC is a multistep process driven by numerous abnormal gene alterations, such as oncogenes activation and tumor suppressor inactivation (26). Particularly, inactivation of tumor suppressor genes modulated by epigenetics is a major player in this multistep carcinogenesis and progression of tongue cancer $(27,28)$. Among them, $\mathrm{H} 3 \mathrm{~K} 9 / \mathrm{HP} 1$ is one of the key epigenetic silencing pathways for gene regulation (29). As an isoforms of $\mathrm{HP} 1, \mathrm{CBX} 3 / \mathrm{HP} 1 \gamma$ has been proved to have various biological functions including 
Table II. Cox proportional hazard model analysis of variables affecting survival in patients with TSCC.

\begin{tabular}{|c|c|c|c|c|c|c|}
\hline \multirow[b]{2}{*}{ Variables } & \multicolumn{3}{|c|}{ Univariate survival analysis } & \multicolumn{3}{|c|}{ Multivariate survival analysis } \\
\hline & Hazard ratio & $95 \% \mathrm{CI}$ & P-value & Hazard ratio & $95 \%$ CI & P-value \\
\hline Age (<60 vs. $\geq 60)$ & 1.468 & $0.749-2.878$ & 0.263 & & & \\
\hline Gender (male vs. female) & 1.947 & $0.954-3.973$ & 0.067 & & & \\
\hline Smoking (yes vs. no) & 1.427 & $0.767-2.657$ & 0.262 & & & \\
\hline Tumor size (T1-2 vs. T3-4) & 1.610 & $0.744-3.488$ & 0.227 & & & \\
\hline Pathological grade (G1 vs. G2-3) & 0.802 & $0.393-1.636$ & 0.544 & & & \\
\hline Cervical node metastasis (N- vs. $\mathrm{N}+$ ) & 3.431 & $1.855-6.345$ & $0.000^{\mathrm{a}}$ & 1.054 & $0.397-2.802$ & 0.916 \\
\hline Clinical stage (I-II vs. III-IV) & 4.257 & $2.249-8.057$ & $0.000^{\mathrm{a}}$ & 3.663 & $1.322-10.146$ & $0.013^{\mathrm{a}}$ \\
\hline CBX3/HP1 $\gamma$ expression (low ${ }^{a}$ vs. high) & 2.967 & $1.370-6.426$ & $0.006^{\mathrm{a}}$ & 2.461 & $1.128-5.370$ & $0.024^{\mathrm{a}}$ \\
\hline
\end{tabular}

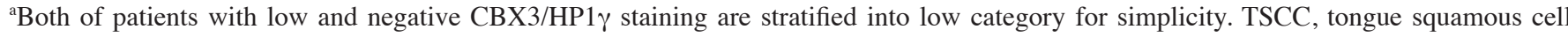
carcinoma.

RNA alternative splicing, DNA damage response, transcription elongation, cell growth and differentiation (7). Notably, highly elevated expression had been found in non-small cell lung cancer, prostate cancer and colorectal cancer $(9,11,25)$ etc. In line with these previous finding, our study showed that $\mathrm{CBX} 3 / \mathrm{HP} 1 \gamma$ was significantly overexpressed in human TSCC, thus indicating that the CBX3/HP1 $\gamma$ might be fostering tumorigenesis in multiple tissues including tongue. To the best of our knowledge, this might be the first study to uncover the abnormal expression pattern of $\mathrm{CBX} 3 / \mathrm{HP} 1 \gamma$ in TSCC. However, the number of patients enrolled in this study was limited. Therefore, more cases from different institutions are needed to definitively confirm the expression pattern of $\mathrm{CBX} 3 / \mathrm{HP} 1 \gamma$ as well as its diagnostic value in TSCC.

There is increasing evidence corroborating the notion that elevated expression of $\mathrm{CBX} 3 / \mathrm{HP} 1 \gamma$ is significantly associated with aggressiveness in various types of cancers (13). For example, elevated $\mathrm{CBX} 3 / \mathrm{HP} 1 \gamma$ is significantly associated with lymph node metastasis and clinical stages in non-small cell lung cancer or with high recurrence rate in prostate cancer $(9,11)$. Similarly, our data showed that overexpression of CBX3/HP1 $\gamma$ was significantly associated with cervical lymph nodes metastasis and clinical stages in TSCC. Moreover, previous studies have demonstrated that $\mathrm{CBX} 3 / \mathrm{HP} 1 \gamma$ can cooperate with MMP3 (matrix metalloproteinase 3), a well-known secretory endopeptidase that degrades extracellular matrices, in transcriptional regulation by serving as a nuclear MMP3-associated protein (NuMAP) (30). Taken together, we propose that CBX3/HP1 $\gamma$ might be an efficient biomarker for cervical node metastasis in TSCC. It will be interesting to explore the expression level of $\mathrm{CBX} 3 / \mathrm{HP} 1 \gamma$ in the metastatic lesions and its clinical significance in further studies.

During the past decades the long term survival rate of TSCC remains disappointing despite the progress in diagnosis and treatment, suggesting that an accurate prognostic marker is highly desired and beneficial in the clinical practice (31). Previous researches showed that $\mathrm{CBX} 3 / \mathrm{HP} 1 \gamma$ expression was associated with patients' survival and was identified as an independent prognostic predictor for patients with colorectal cancer, non-small cell lung cancer $(11,25)$.
For example, Slezak J et al (9) found that high expression of $\mathrm{CBX} 3 / \mathrm{HP} 1 \gamma$ positively correlated with overexpression of Ki67 and predicted unfavorable prognosis in patients with prostate cancer. In agreement with these findings, our results indicated that patients with low $\mathrm{CBX} 3 / \mathrm{HP} 1 \gamma$ expression had significantly longer survival comparing to those with high $\mathrm{CBX} 3 / \mathrm{HP} 1 \gamma$. Furthermore, univariate analysis identified CBX3/HP1 $\gamma$ expression as an independent prognostic factor affecting survival of patients with TSCC. Thus, the expression status of $\mathrm{CBX} 3 / \mathrm{HP} 1 \gamma$ might offer valuable information for predicting patients' prognosis and effective follow-up management.

Increasing evidence had uncovered that $\mathrm{CBX} 3 / \mathrm{HP} 1 \gamma$ was critically involved in tumorigenesis by promoting cell proliferation via regulating the expression of $\mathrm{P} 21$ or cyclin dependent kinases 6 (CDK6) during cell cycle $(7,25)$. In addition, $\mathrm{CBX} 3 / \mathrm{HP} 1 \gamma$ was demonstrated to have novel function in the epigenetic regulation of both cell differentiation and cancer development in various types of cancers (10). In particular, Michael Su et al found that reducing the levels of $\mathrm{Cbx} 3 / \mathrm{HP} 1 \gamma$ could enhance tumor-killing capacity on CD8+ T cells (32). Taken these findings together, we suppose that $\mathrm{Cbx} 3 / \mathrm{HP} 1 \gamma$ serve as not only a novel cancer biomarker of high value in diagnosis and prognosis, but also an effective target for gene therapy against various human cancers. Therefore, further researches are solely needed to uncover the roles and mechanisms of $\mathrm{Cbx} 3 / \mathrm{HP} 1 \gamma$ during tongue tumorigenesis.

In conclusion, $\mathrm{Cbx} 3 / \mathrm{HP} 1 \gamma$ is aberrantly overexpressed in TSCC tissues. CBX3/HP1 $\gamma$ expression is an independent prognostic factor of patients with TSCC, suggesting that Cbx3/HP1 $\gamma$ may be a candidate prognostic marker for TSCC patients. More studies are warranted to gain the insight into the mechanism of $\mathrm{CBX} 3 / \mathrm{HP} 1 \gamma$ playing during the tumorigenesis and progression in TSCC.

\section{Acknowledgements}

The authors would like to thank Professor WuGuo Deng and Mr. DingBo Shi of The State Key Laboratory of Oncology in South China (Guangzhou, China) for their help during the experiment. 


\section{Funding}

No funding was received.

\section{Availability of data and materials}

All data generated or analyzed during this study are included in this published article.

\section{Authors' contributions}

AY designed the study. XS collected the patients' samples and performed the statistical analysis. $\mathrm{HZ}$ and XF performed the experiments and were major contributors in writing the manuscript. All authors read and approved the final manuscript.

\section{Ethics approval and consent to participate}

The experimental protocol was established, according to the ethical guidelines of the Helsinki Declaration and was approved by the Human Ethics Committee of Sun Yan-sen University Cancer Centre. Written informed consent was obtained from individual or guardian participants.

\section{Consent for publication}

Not applicable.

\section{Competing interests}

The authors declare that they have no competing interests.

\section{References}

1. Siegel RL, Miller KD and Jemal A: Cancer statistics, 2017. CA Cancer J Clin 67: 7-30, 2017.

2. Chi AC, Day TA and Neville BW: Oral cavity and oropharyngeal squamous cell carcinoma-an update. CA Cancer J Clin 65: 401-421, 2015

3. Duz MB, Karatas OF, Guzel E, Turgut NF, Yilmaz M, Creighton CJ and Ozen M: Identification of miR-139-5p as a saliva biomarker for tongue squamous cell carcinoma: A pilot study. Cell Oncol (Dordr) 39: 187-193, 2016.

4. Li Z, Wang Y, Qiu J, Li Q, Yuan C, Zhang W, Wang D, Ye J, Jiang $\mathrm{H}$, Yang $\mathrm{J}$ and Cheng J: The polycomb group protein EZH2 is a novel therapeutic target in tongue cancer. Oncotarget 4: 2532-2549, 2013.

5. Canzio D, Larson A and Narlikar GJ: Mechanisms of functional promiscuity by HP1 proteins. Trends Cell Biol 24 377-386, 2014.

6. Yuan C, Li Z, Qi B, Zhang W, Cheng J and Wang Y: High expression of the histone demethylase LSD1 associates with cancer cell proliferation and unfavorable prognosis in tongue cancer. J Oral Pathol Med 44: 159-165, 2015.

7. Fan Y, Li H, Liang X and Xiang Z: CBX3 promotes colon cancer cell proliferation by CDK6 kinase-independent function during cell cycle. Oncotarget 8: 19934-19946, 2017.

8. Minc E, Courvalin JC and Buendia B: HP1gamma associates with euchromatin and heterochromatin in mammalian nuclei and chromosomes. Cytogenet Cell Genet 90: 279-284, 2000.

9. Slezak J, Truong M, Huang W and Jarrard D: HP1 $\gamma$ expression is elevated in prostate cancer and is superior to Gleason score as a predictor of biochemical recurrence after radical prostatectomy. BMC Cancer 13: 148, 2013.

10. Takanashi M, Oikawa K, Fujita K, Kudo M, Kinoshita M and Kuroda M: Heterochromatin protein 1gamma epigenetically regulates cell differentiation and exhibits potential as a therapeutic target for various types of cance. Am J Pathol 174: 309-316, 2009.
11. Zhou J, Bi H, Zhan P, Chang C, Xu C, Huang X, Yu L, Yao X and Yan J: Overexpression of HPl $\gamma$ is associated with poor prognosis in non-small cell lung cancer cell through promoting cell survival. Tumour Biol 35: 9777-9785, 2014.

12. Edge SB and Compton CC: The American joint committee on cancer: The 7th edition of the AJCC cancer staging manual and the future of TNM. Ann Surg Oncol 17: 1471-1474, 2010.

13. Zheng X, Jia B, Lin X, Han J, Qiu X, Chu H, Sun X, Hu W, Pan J, Chen J and Zhao J: FRMD4A: A potential therapeutic target for the treatment of tongue squamous cell carcinoma. Int J Mol Med 38: 1443-1449, 2016

14. Talbot SG, Estilo C, Maghami E, Sarkaria IS, Pham DK, O-charoenrat P, Socci ND, Ngai I, Carlson D, Ghossein R, et al: Gene expression profiling allows distinction between primary and metastatic squamous cell carcinomas in the lung. Cancer Res 65: 3063-3071, 2005

15. Estilo CL, O-charoenrat P, Talbot S, Socci ND, Carlson DL, Ghossein R, Williams T, Yonekawa Y, Ramanathan Y, Boyle $\mathrm{JO}$, et al: Oral tongue cancer gene expression profiling: Identification of novel potential prognosticators by oligonucleotide microarray analysis. BMC Cancer 9: 11, 2009.

16. Kuriakose MA, Chen WT, He ZM, Sikora AG, Zhang P, Zhang ZY, Qiu WL, Hsu DF, McMunn-Coffran C, Brown SM, et al: Selection and validation of differentially expressed genes in head and neck cancer. Cell Mol Life Sci 61: 1372-1383, 2004.

17. Ye H, Yu T, Temam S, Ziober BL, Wang J, Schwartz JL, Mao L, Wong DT and Zhou X: Transcriptomic dissection of tongue squamous cell carcinoma. BMC Genomics 9: 69, 2008.

18. Suvà ML, Riggi N and Bernstein BE: Epigenetic reprogramming in cancer. Science 339: 1567-1570, 2013.

19. Zeng W, Ball AR Jr and Yokomori K: HP1: Heterochromatin binding proteins working the genome. Epigenetics 5: 287-292, 2010.

20. Maison C and Almouzni G: HP1 and the dynamics of heterochromatin maintenance. Nat Rev Mol Cell Biol 5: 296-304, 2004.

21. Bártová E, Malyšková B, Komůrková D, Legartová S, Suchánková J, Krejčí $\mathrm{J}$ and Kozubek S: Function of heterochromatin protein 1 during DNA repair. Protoplasma 254: 1233-1240, 2017.

22. Dialynas GK, Vitalini MW and Wallrath LL: Linking heterochromatin protein 1 (HP1) to cancer progression. Mutat Res 647: 13-20, 2008.

23. Saini V, Hose CD, Monks A, Nagashima K, Han B, Newton DL, Millione A, Shah J,Hollingshead MG, Hite KM, et al: Identification of CBX3 and ABCA5 as putative biomarkers for tumor stem cells in osteosarcoma. PLoS One 7: e41401, 2012.

24. Lomberk G, Bensi D, Christensen T, Salisbury J and Urrutia R: HP1 $\gamma$ has a significant impact on cell cycle progression through the regulation of $\mathrm{G} 2 / \mathrm{M}$, centrosome biology and, chromosomal stability in pancreatic cancer cells. Pancreas 35: 412, 2007.

25. Liu M, Huang FF, Zhang D, Ju J, Wu XB, Wang Y, Wang Y, Wu Y, Nie M, Li Z, et al: Heterochromatin protein HP1 $\gamma$ promotes colorectal cancer progression and is regulated by miR-30a. Cancer Res 75: 4593-4604, 2015.

26. Scully $\mathrm{C}$ and Bagan J: Oral squamous cell carcinoma overview. Oral Oncol 45: 301-308, 2009

27. González-Ramírez I, Soto-Reyes E, Sánchez-Pérez Y, Herrera LA and García-Cuellar C: Histones and long non-coding RNAs: The new insights of epigenetic deregulation involved in oral cancer. Oral Oncol 50: 691-695, 2014

28. Mascolo M, Siano M, Ilardi G, Russo D, Merolla F, De Rosa G and Staibano S: Epigenetic disregulation in oral cancer. Int J Mol Sci 13: 2331-2353, 2012.

29. Nestorov P, Tardat $M$ and Peters AH: H3K9/HP1 and Polycomb: two key epigenetic silencing pathways for gene regulation and embryo development. Curr Top Dev Biol 104: 243-291, 2013.

30. Eguchi T, Calderwood SK, Takigawa M, Kubota S and Kozaki KI: Intracellular MMP3 promotes HSP gene expression in collaboration with chromobox proteins. J Cell Biochem 118: 43-51, 2017.

31. Hu H, Wang Y, Li Z, Zhu Y, Zhang W, Wang D, Lin T, Yang J, Wang Y and Cheng J: Overexpression of suppressor of zest 12 is associated with cervical node metastasis and unfavorable prognosis in tongue squamous cell carcinoma. Cancer Cell Int 17: 26, 2017.

32. Sun M, Ha N, Pham DH, Frederick M, Sharma B, Naruse C, Asano M, Pipkin ME, George RE and Thai TH: Cbx3/HP1 $\gamma$ deficiency confers enhanced tumor-killing capacity on $\mathrm{CD} 8+\mathrm{T}$ cells. Sci Rep 7: 42888, 2017. 